\title{
Development of quantitative DNA cleavage assay for XPG endonuclease activity using endogenous nuclear proteins in human cell lines
}

\author{
PREEYAPORN KOEDRITH and YOUNG ROK SEO \\ Department of Life Science, Dongguk University-Seoul, 26 Pil-dong 3-ga, Jung-gu, Seoul 100-715, Republic of Korea
}

Received May 12, 2011; Accepted July 1, 2011

DOI: $10.3892 /$ or.2011.1424

\begin{abstract}
XPG, a structure-specific DNA endonuclease responsible for the 3 ' incision of DNA lesions during nucleotide excision repair (NER), is associated with high risk of skin cancer as well as skeletal, neurological and developmental abnormalities when functionally defective. These observations have led to the model wherein the endonuclease activity of XPG is important for NER. Herein, we first demonstrate a sensitive assay of XPG cleavage activity using direct nuclear extracts as an XPG source. This method provided quantitative evaluation of the activity of endogenous XPG endonuclease derived from cells with high reproducibility. Our new assay takes advantage of 3'-end oligolabeling of the bubble-shaped substrate. Our results demonstrate efficient cleavage of the model substrate in two XPG wild-type cell lines (human fibroblasts and RKO colon cancer cells) in a time- and dose-dependent manner. In addition, XPG-deficient cells manifested lower cleavage activity relative to normal XPG cells, indicating that the incision activity of XPG was intrinsic in our methodology. It was also found that $7 \mathrm{mM} \mathrm{MgCl}$ and buffer $\mathrm{pH} 6.8$ resulted in optimal endonucleolytic activity. Based on these results, our modified methodology has potential for quantitative monitoring of XPG cleavage activity in any cell type or tissue of interest.
\end{abstract}

\section{Introduction}

Nucleotide excision repair (NER) pathway is considered to be a major DNA repair system for the elimination of bulky chemical adducts as well as UV photoproducts (1). In humans, defects in XPG 'xeroderma pigmentosum (XP) of the complementation group G', a crucial enzyme in the NER pathway, result in cancer-prone syndromes with acute UV

Correspondence to: Dr Young Rok Seo, Department of Life Science, Dongguk University-Seoul, 26 Pil-dong 3-ga, Jung-gu, Seoul 100-715, Republic of Korea

E-mail: seoyr@dongguk.edu

Key words: xeroderma pigmentosum, XPG endonuclease, ERCC1$\mathrm{XPF}$, DNA lesion, nucleotide excision repair sensitivity and high incidence of skin cancer $(2,3)$. Overall, the evidence suggests that XPG protein plays a vital role in DNA repair and consequently maintenance of genomic stability.

XPG protein is a structure-specific endonuclease that cleaves substrates with a defined polarity during NER (4). In vitro studies on the catalytic activity of purified human XPG found that its preferred substrates are artificial DNA structures (bubbles, splayed arms, stem-loops, and flap substrates) $(4,5)$. XPG protein has a molecular weight of $135 \mathrm{kDa}$ and belongs to the structure-specific Fen1 (Flap endonuclease 1) family (6). Within its N-terminal and internal regions, XPG shares sequence similarities with a family of other nucleases, including bacteriophage T4 RNase $\mathrm{H}$ (7). There are conserved acidic residues in the active site of $\mathrm{RNase} H$ that can chelate two catalytic magnesium (Mg) ions (7). These same acidic residues in XPG are potentially involved in hydrolysis and therefore might be involved in XPG-DNA binding.

During NER, sequential biochemical processes mediate recognition of damaged bases, incision of 26-29 nucleotides, removal of the damaged patch, filling of the gap, and ligation (8). In the incision step, dual incisions of opposite polarity near the junction of the unpaired and duplex DNA are catalyzed by two different endonucleases. In humans, XPG protein and the ERCC1-XPF complex mediate the 3'- and 5'-incisions, respectively (9). Both endonucleases display structure specificity on model DNA substrates. Extensive in vitro biochemical studies on DNA incision have been conducted using overexpressed recombinant XPG protein after its purification to apparent homogeneity $(10,11)$. The evidence shows that XPG plays a structural role in assembly of the preincision complex. In addition, purified XPG has also been shown to have endonucleolytic as well as repair activities (9). Moreover, this enzyme has been characterized under various conditions (model substrate structures, cofactors, $\mathrm{pH}$, and temperatures) $(5,12)$.

Defining the exact cleavage activity of endogenous nuclear XPG is of considerable interest. Specifically, the dual incision activities of XPG and ERCC1-XPF complex on the 3'- and 5'-sides of damaged DNA strands, respectively, is of concern (9). On the other hand, the 5'-incision activity of the ERCC1-XPF complex hinders XPG 3'-cleavage activity when conventional $5^{\prime}$-end oligolabeling is applied. Hence, 3 '-end oligolabeling is an alternative approach to obtaining 
satisfactory results when using intracellular protein extract. This suggests that the overexpression and purification of target XPG are not prerequisites for the XPG assay.

In this study, we perform quantitative endonuclease assay of human nuclear XPG. Incubation of 3'-radiolabeled 'bubble', a preferential substrate of XPG, with nuclear extract successfully resulted in structure-specific DNA cleavage. Nuclear protein extracted from normal fibroblasts and human colon cancer RKO cells was compared to that of XPG-deficient cells (XPG null fibroblast and XPG knockdown RKO cells, respectively). Furthermore, optimization under different conditions was also conducted in each cell type. The major advantage of direct nuclear XPG-based assay is that it is non-laborious, cost-effective, and highly reproducible. This modified nuclear XPG assay might be applied toward most cell types as well as tissues of interest.

\section{Materials and methods}

Cell culture. Human colon cancer RKO cells (ATCC No. CRL-257) were cultured in RPMI-1640 medium supplemented with $10 \%$ fetal bovine serum (FBS) while XPG shRNA (short-hairpin RNA) knockdown cells were grown in RPMI-1640 medium containing 10\% FBS and $0.5 \mu \mathrm{g} / \mathrm{ml}$ of puromycin. Normal human fibroblasts (GM08399) and XPG null fibroblast (GM16398) cells (Coriell Cell Repository, Camden, NJ, USA) were cultivated in DMEM medium containing $10 \% \mathrm{FBS}$. The cultures were incubated at $37^{\circ} \mathrm{C}$ and $5 \% \mathrm{CO}_{2}$.

Stable knockdown of XPG using shRNA vector was successfully established as follows: In brief, Escherichia coli clone harboring retroviral vector pSM2c containing XPG-specific shRNA target (Open Biosystems, USA) was subjected to plasmid extraction using a HiSpeed Plasmid Midi kit (Qiagen, Germany). The purified plasmids were then submitted for sequencing to verify the XPG-specific shRNA target (sense: CCCACAGACTCAGTTCCAA and antisense: TTGGAACTGAGTCTGTGGG). XPG shRNA knockdown cells were prepared using transfection reagent Fugen6 (Roche, Germany), following the manufacturer's manual.

Preparation of cellular nuclear extract. Nuclear extract was prepared using a Caymans Nuclear Extraction kit (Caymanchem, USA) with minor modifications. Briefly, 1×10 RKO cells and fibroblasts were seeded in 100-mm culture dishes. After centrifugation, cell pellets were twice washed in $5 \mathrm{ml}$ of ice-cold phosphate buffered saline (PBS) in the presence of phosphatase inhibitors and then centrifuged. Subsequently, the pellets were resuspended in $500 \mu \mathrm{l}$ of chilled (1X) hypotonic buffer and incubated on ice for $15 \mathrm{~min}$. Nonidet P-40 (50 $\mu \mathrm{l}$, $10 \%$ ) was added to lyse the cell membranes, followed by brief centrifugation. The pelleted nuclei were lysed in $50 \mu \mathrm{l}$ of chilled (1X) complete nuclear extraction buffer containing a mixture of protease and phosphatase inhibitors, followed by consecutive vortexing. After centrifugation, the nuclear supernatant was collected and stored at $-80^{\circ} \mathrm{C}$. The protein concentration was then quantified.

Preparation of 3'-end radiolabeled oligonucleotide. The bubble oligonucleotide was employed as a specific substrate for the XPG cleavage assay (4). One strand was initially 3'-labeled with terminal transferase (NEB, UK) and $\left[\alpha{ }^{32} \mathrm{P}\right]-$ dATP. In brief, 20 pmol of bubble-up oligonucleotides (5' CCA GTG ATC ACA TAC GCT TTG CTA GGA CAT CCC CCC CCC CCC CCC CCC CCC CCC CCC CCC CAG TGC CAC GTT GTA TGC CCA CGT TGA CCG 3') was added in a labeling reaction mixture $(50 \mu \mathrm{l})$ containing $(1 \mathrm{X})$ terminal transferase buffer, $250 \mu \mathrm{M} \mathrm{CoCl}{ }_{2}, 100 \mu \mathrm{M}\left[\alpha-{ }^{32} \mathrm{P}\right]-\mathrm{dATP}$, and 10 units of terminal transferase. After incubation for $30 \mathrm{~min}$ at $37^{\circ} \mathrm{C}$, the reaction was inactivated by heating at $70^{\circ} \mathrm{C}$ for $10 \mathrm{~min}$. The resulting labeled bubble-up was precipitated with $1 \mu \mathrm{l}$ of glycogen and $36 \mu \mathrm{l}$ of isopropanol, followed by centrifugation at 15,000 $\mathrm{rpm}$ for $10 \mathrm{~min}$ at room temperature. Finally, an annealing step was performed by adding $38 \mu \mathrm{l}$ (1X) of annealing buffer (10 mM Tris $\mathrm{pH} 8.0,1 \mathrm{mM}$ EDTA, and $100 \mathrm{mM} \mathrm{NaCl}$ ) along with an equal amount of unlabeled bubble-down oligonucleotides (5' CGG TCA ACG TGG GCA TAC AAC GTG GCA CTG TTT TTT TTT TTT TTT TTT TTT TTT TTT TTT ATG TCC TAG CAA AGC GTA TGT GAT $3^{\prime}$ ), followed by incubation in a water bath at $95^{\circ} \mathrm{C}$ and a cooling down period.

Preparation of 5'-end radiolabeled oligonucleotide. The procedure for radiolabeling of the 5'-terminus of the bubble substrate was performed as described in 'the preparation of 3 '-end radiolabeled oligonucleotide', or as otherwise indicated. One strand was initially 5'-labeled with T4 polynucleotide kinase (Promega, USA) and $\left[\gamma^{-32} \mathrm{P}\right]$-ATP. Then, $20 \mathrm{pmol}$ of bubble-up oligonucleotides was added to the labeling reaction mixture $(50 \mu \mathrm{l})$ containing $(1 \mathrm{X}) \mathrm{T} 4$ polynucleotide kinase buffer $\left[\gamma^{32} \mathrm{P}\right]$-ATP, and 20 units of T4 polynucleotide kinase. Afterwards, downstream steps were carried out as aforementioned in 'the preparation of 3'-end radiolabeled oligonucleotide'.

Preparation of radiolabeled DNA marker. Radiolabeling of the 5'-terminus of the DNA marker was accomplished using $\left[\gamma^{32} \mathrm{P}\right]$-ATP and T4 polynucleotide kinase. The DNA size marker used is dephosphorylated $\phi X 174$ DNA/Hinf I (Promega). Basically, 50-200 ng of DNA marker was mixed into a $10 \mu \mathrm{l}$ reaction mixture [(1X) T4 polynucleotide kinase buffer, $2 \mathrm{mM}\left[\gamma^{32} \mathrm{P}\right]$-ATP, and 10 units of T4 polynucleotide kinase] and incubated for $10 \mathrm{~min}$ at $37^{\circ} \mathrm{C}$. Reactions were stopped by adding an equal volume of (1X) sample loading buffer (90\% formamide, $5 \mathrm{mM}$ EDTA, $0.1 \%$ bromophenol blue, and $0.1 \%$ xylene cyanol). Samples were heated at $95^{\circ} \mathrm{C}$ for $3 \mathrm{~min}$ before gel electrophoresis.

Nuclear XPG cleavage assay. XPG endonuclease assay was conducted with some modifications based on in vitro assay procedures $(5,13)$. Under standard conditions, the indicated amount of nuclear extract was mixed with 1 pmol of radiolabeled 'bubble' substrate in $(8 \mu \mathrm{l})$ reaction buffer [ $25 \mathrm{mM}$ HEPES pH 6.8, $10 \%$ glycerol, $2 \mathrm{mM} \mathrm{MgCl}_{2}, 50 \mu \mathrm{g} / \mathrm{ml}$ of bovine serum albumin, and $1 \mathrm{mM} \mathrm{DTT]}$ at $37^{\circ} \mathrm{C}$ for $30 \mathrm{~min}$, or as otherwise indicated. The concentrations of divalent ions as cofactors $\left(\mathrm{MgCl}_{2}\right.$ and $\left.\mathrm{MnCl}_{2}\right)$ varied, ranging from 2-10 mM (Fig. 3). Reactions were stopped by adding an equal volume of (1X) sample loading buffer. Samples were subjected to heating at $95^{\circ} \mathrm{C}$ for $3 \mathrm{~min}$ and then separated by $12 \%$ sodium dodecyl 


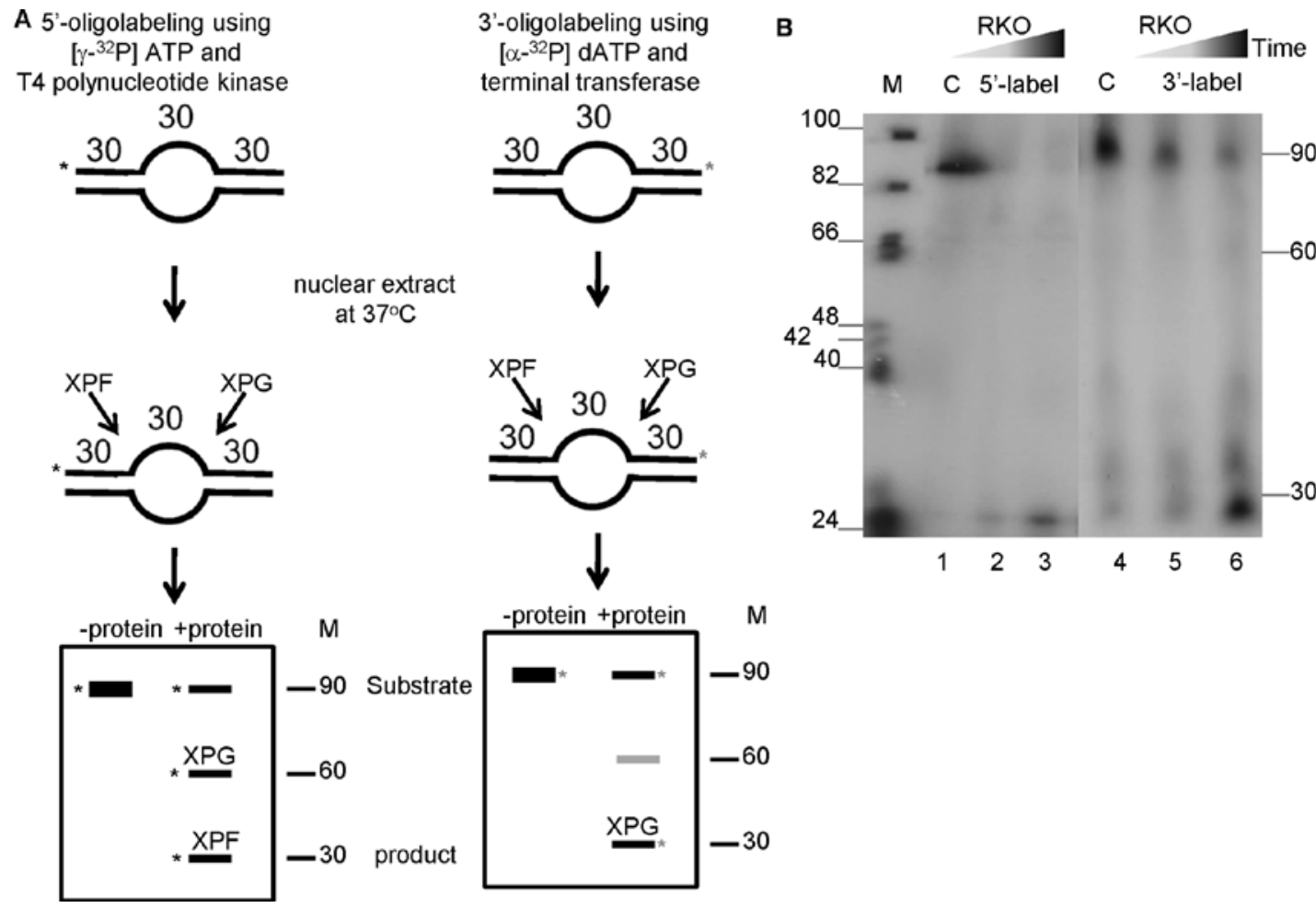

Figure 1. Modified endonuclease XPG assay. (A) Scheme representing advantageous assay of XPG activity with direct use of nuclear extract via 3' oligolabeling, in comparison to $5^{\prime}$-oligolabeling-based approach. Asterisk $\left(^{*}\right)$ indicates the orientation of radiolabeling. Using 3 '-oligolabeling, this strategy renders the XPG cleavage assay possible with simultaneous use of XPG-containing nuclear extract. (B) XPG incision activity by 3'-end oligolabeling (right panel) compared to 5'-end oligolabeling (left panel). Instead of applying conventional 5'-end-labeled bubble (lanes 1-3), 3'-end-labeled bubble was incubated without or with endogenous XPG-derived protein (lanes 4-6) at $37^{\circ} \mathrm{C}$ for 10 and $30 \mathrm{~min}$, respectively. C, negative control; M, DNA marker.

sulfate-polyacrylamide gel electrophoresis (SDS-PAGE) at $1,000 \mathrm{~V}$ for $1 \mathrm{~h}$. Next, the gel was transferred onto Whatman ${ }^{\circledR}$ 3-mm paper, dried, and visualized by autoradiography. All assays were performed independently in duplicate.

Determination of nuclear XPG by Western blot analysis. Nuclear proteins were separated by $10 \%$ SDS-PAGE and transferred onto polyvinylidene fluoride (PVDF) membranes, which were then blocked. XPG protein was detected using a mouse monoclonal antibody against XPG and peroxidase-conjugated goat antimouse IgG (Santa Cruz Biotechnology, USA) as a secondary antibody. Chemiluminescence was subsequently enhanced (ECL Plus Western blotting detection kit, GE Healthcare, UK). CyclinB1 was used as a protein loading control. The entire procedure was performed three times independently.

\section{Results}

Development of XPG cleavage assay with 3'-tailing of substrate. In previous studies, preparation of relatively pure XPG was required for XPG cleavage assay $(10,11)$. Especially, the ERCC1-XPF complex can interfere with this assay due to its endonucleolytic activity at the 5'-terminus of the 5'-end labeled substrate during the dual incision step (9). To circumvent this problem, 3 -end oligolabeling of the substrate using $\left[\alpha-{ }^{32} \mathrm{P}\right]$-dATP was alternatively designated for the XPG endonuclease assay instead of 5 '-end oligolabeling with $\left[\gamma^{-32} \mathrm{P}\right]$-ATP (Fig. 1A). This approach enabled us to successfully establish the quantitative XPG endonuclease assay using XPG-derived nuclear extract.
Normal fibroblasts and RKO cells were subjected to nuclear extraction. In several previous investigations, a bubble-shaped structure was selectively applied as an XPG-specific DNA substrate since it might resemble an intermediate DNA structure in NER (14).

Under standard conditions, incubation of nuclear protein with $3^{1}{ }^{32} \mathrm{P}$-end-labeled bubble was conducted. As shown in Fig. 1B, the substrate fraction in presence of nuclear extract was remarkably decreased (lanes 5 and 6) compared to that in the absence of nuclear extract (lane 4). Incubation with nuclear extract showed cleavage products with a mobility of $\sim 30$ nucleotides, indicating that structure-specific cleavage was an intrinsic XPG activity. The result suggests efficient DNA cleavage of the specific model substrate using the nuclear protein in our XPG assay. In addition, our modified assay can be practically applied to different cell types since there was no apparent difference in DNA cleavage pattern between the tested cell types. The appearance of the second cleaved band might have been due to additional XPG cutting at the proximal site 3-5 nucleotides away from the single strand/duplex junction $(5,15)$.

Based on the $5^{1}{ }^{32} \mathrm{P}$-end-oligolabeling procedure, the incised DNA band with expected mobility of $\sim 60$ nucleotides did not appear, whereas the digested product with much lower mobility was noticeably present (Fig. 1B: lanes 1-3). A possible explanation for this phenomenon might be the participation of the ERCC1-XPF complex with 5'-incision activity (Fig. 1A) (9). However, this does not exclude catalytic activity of other nuclease proteins in the nuclear extract fraction. 
A

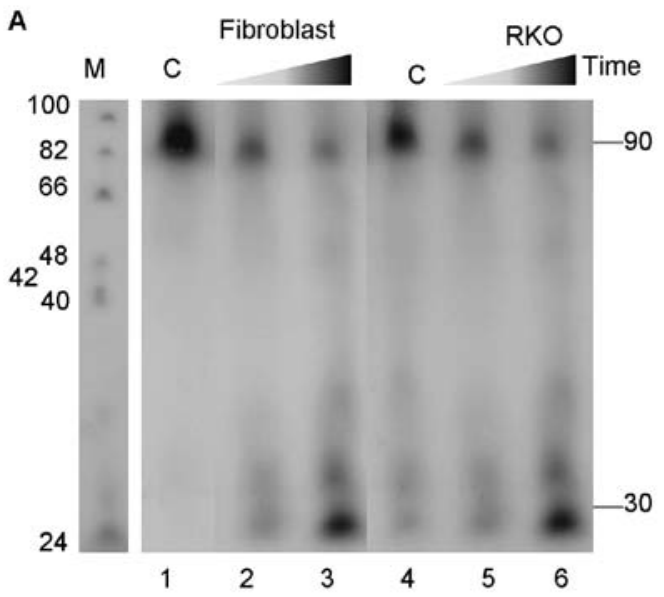

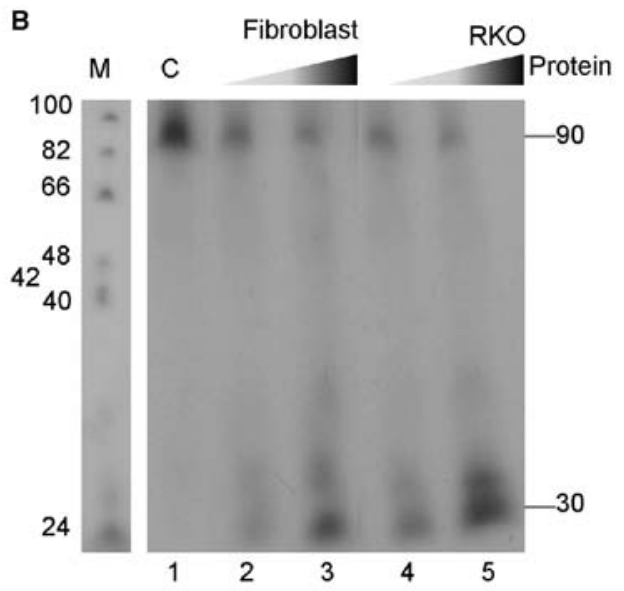

Figure 2. Analysis of intrinsic nuclear XPG activity. The incision activity of endogenous nuclear XPG was examined in a (A) time- or (B) dose-dependent manner. Standard incision reaction was conducted with varied incubation times (A) as follows: 10 (lane 2 or 5) and 30 min (lane 3 or 6) as well as with various amounts of nuclear protein (B) as follows: $50 \mathrm{ng}$ (lane 2 or 4) and $100 \mathrm{ng}$ (lane 3 or 5) for fibroblasts and RKO cells, respectively. C, negative control; M, DNA marker.

A

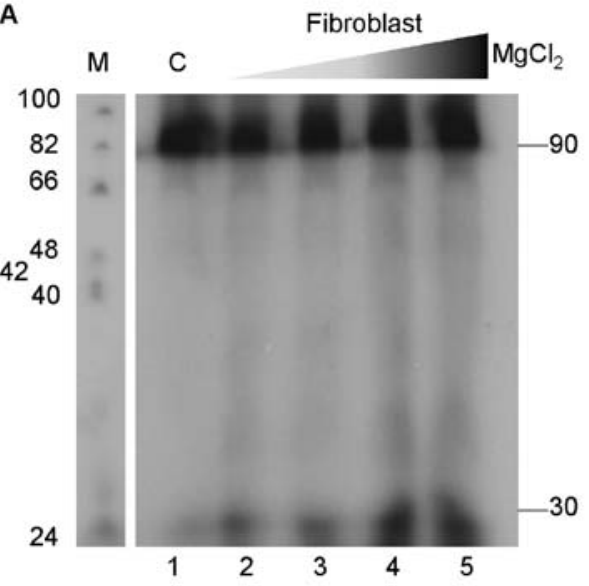

B

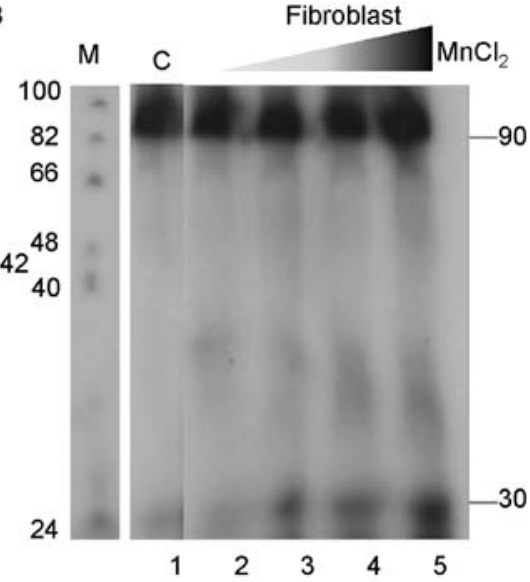

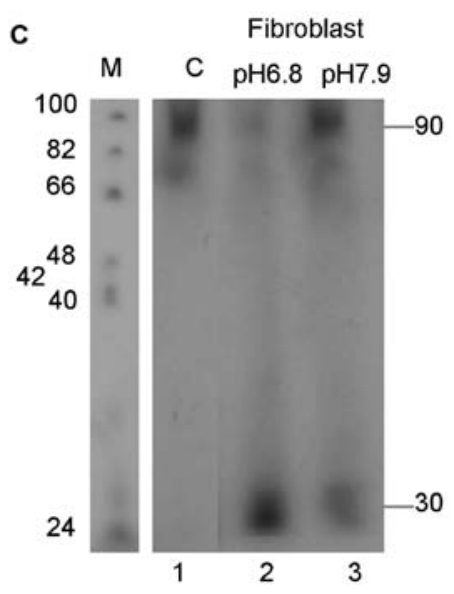

Figure 3. Effect of important factors on XPG endonucleolytic assay. XPG endonuclease activity with 3'-radiolabeled bubble substrate (100 pmol) and $100 \mathrm{ng}$ of nuclear XPG-derived protein in reaction buffer at $37^{\circ} \mathrm{C}$ for 30 min was evaluated using (A) $\mathrm{MgCl}_{2}$ and (B) $\mathrm{MnCl}_{2}$, with increasing concentration as follows: $2 \mathrm{mM}$ (lane 2), $5 \mathrm{mM}$ (lane 3), $7 \mathrm{mM}$ (lane 4), and $10 \mathrm{mM}$ (lane 5) as well as (C) buffer pH. C, negative control; M, DNA marker.

Analysis of nuclear XPG endonuclease assay in a time- or dosedependent manner. Based on the above, the incision activity of XPG on bubble substrate was subjected to tests in a time- or dose-dependent manner. Under the conditions of standard XPG assay, unless otherwise indicated, incubation of nuclear extract with $3^{132} \mathrm{P}$-end-labeled bubble substrate was carried out in a timedependent manner. Nuclear extract XPG was capable of specific cutting the substrate. As shown in Fig. 2A, the cleaved product 


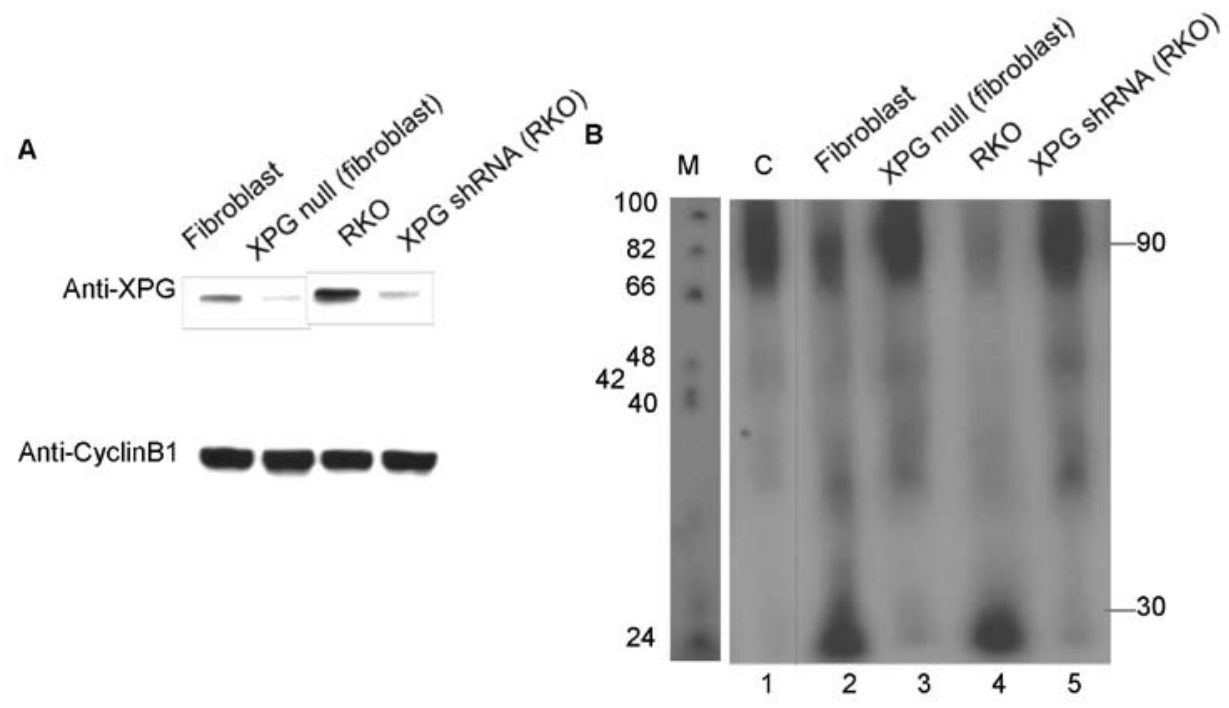

Figure 4. Quantitative XPG endonuclease assay in different cell lines. (A) Relative quantity of XPG protein in basal normal XPG cells (fibroblasts and RKO) compared with XPG-deficient cells (XPG null fibroblasts and XPG shRNA knockdown RKO cells, respectively) was verified by Western blot analysis. CyclinB1 was loading control. (B) The modified quantitative XPG cleavage assay using endogenous nuclear protein was established in basal normal XPG cells (fibroblasts and RKO) compared to XPG-deficient cells (XPG null fibroblasts and XPG shRNA knockdown RKO cells, respectively). C, negative control; M, DNA marker.

exhibited consistent migration rates, which strongly indicates that the cleaved product was attributable to intrinsic XPG endonuclease activity. Furthermore, there was an increased amount of the 30 -nucleotide cleaved product with a longer incubation time, which was conversely proportional to amount of uncut substrate (Fig. 2A). This implies that DNA cleavage by nuclear extract XPG was time-dependent. In parallel experiments, the dependency of XPG endonuclease reaction on protein concentration (50-100 ng) was also examined. Similarly, XPG cleavage occurred in a dose-dependent fashion (Fig. 2B). Overall, these results demonstrate that reconstitution of the XPG endonuclease assay using nuclear extract was successful. Furthermore, XPG incision was both time- and dose-dependent.

Characterization of important factors affecting nuclear XPG endonuclease reaction. Initial studies have demonstrated that, under a wide range of concentrations, either $\mathrm{Mg}^{2+}$ or $\mathrm{Mn}^{2+}$ acting as an enzyme cofactor is required for XPG scission $(5,12)$. Both divalent $\mathrm{MgCl}_{2}$ and $\mathrm{MnCl}_{2}$ influence the conformation of DNA substrates, which can affect protein activity under certain conditions $(7,12)$. Consequently, different parameters important for XPG cleavage (divalent cofactors and reaction buffer $\mathrm{pH}$ ) were tested their effects on XPG catalytic efficiency. After the XPG cleavage reaction was reconstituted under various individual factors, the DNA banding patterns and intensities were evaluated.

In the presence of either $\mathrm{MgCl}_{2}$ or $\mathrm{MnCl}_{2}(2-10 \mathrm{mM})$, incubation of nuclear extract with 3 '-radiolabeled bubble was performed under standard conditions unless otherwise stated. It was discovered that an increasing concentration of $\mathrm{MgCl}_{2}$ resulted in improved XPG reaction efficiency (Fig. 3A). Obviously, $7 \mathrm{mM} \mathrm{MgCl}_{2}$ yielded the most efficient reaction in the tested cells, indicating an optimal XPG reaction. This might have been the result of different substrate conformations under varying salt concentrations. Similarly, $\mathrm{MnCl}_{2}$ had a mild influence on XPG endonucleolytic activity (Fig. 3B). Therefore, these results reveal that XPG cleavage was more strongly dependent on $\mathrm{MgCl}_{2}$ than on $\mathrm{MnCl}_{2}$.

Since optimal binding of XPG to DNA substrate has been defined over a broad range of pH 6-8.5 (12). In previous studies, XPG endonuclease assays have been generally reconstituted in either pH 6.8 (4) or pH 7.9 buffer (15). To investigate which buffer $\mathrm{pH}$ (6.8 or 7.9) yields optimal XPG incision efficiency of nuclear extract, HEPES buffer at each particular $\mathrm{pH}$ was employed. As expected, XPG endonuclease assay reconstituted in buffer $\mathrm{pH} 6.8$ resulted in more efficient XPG activity rather than buffer pH 7.9 (Fig. 3C). The low pI (5.2) of XPG might be one of the reasons for optimal XPG cleavage at pH 6.8 (16).

Comparison of XPG activity between XPG normal and $X P G$-deficient cells. After optimization, quantitative analysis of XPG endonuclease activity was subsequently conducted in human fibroblasts as well as human colon cancer RKO cells in comparison to XPG-deficient cells. Strikingly, incubation of XPG nuclear extract in the $\mathrm{pH} 6.8$ reaction buffer containing $7 \mathrm{mM} \mathrm{MgCl} 2$ resulted in relatively higher XPG-mediated DNA incision in normal fibroblast cells, when compared to that in XPG null cells (Fig. 4B: lanes 2 and 3, respectively). Similarly, XPG-cut DNA efficiency was higher in RKO cells relative to XPG shRNA knockdown cells (Fig. 4B: lanes 4 and 5). Moreover, there was no difference in the quantity of protein loading by Western analysis (Fig. 4A). This result suggests that cleavage of the bubble-shaped DNA was intrinsic to XPG activity under optimal conditions.

\section{Discussion}

Due to the importance of XPG protein in DNA repair processes, the evaluation of specific XPG endonuclease activity has garnered strong interest $(17,18)$. This study was conducted to develop a method for determining XPG endonuclease activity derived from living cells. The method 
comprised of oligolabeling at 3'-termini using terminal transferase and $\left[\alpha^{32} \mathrm{P}\right]-\mathrm{dATP}$ as well as optimization of necessary parameters. The rationale for these steps is as follows. NER is thought to operate by the sequential assembly of repair factors involved at DNA damage sites (19). During the formation of an opened DNA structure, XPG including XPA and RPA join in a complex to form a stable open structure. Afterwards, recruitment of ERCC1-XPF by XPA results in dual incision at the 5'- and 3'-termini by ERCC1-XPF and XPG, respectively. Our studies using nuclear extract, presence of additional structurespecific endonuclease, the ERCC1-XPF complex, with specific 5 '-cutting at the damage site was thus rationally concerned. The 5' incision via ERCC1-XPF can interfere with the XPG endonuclease assay when conventional 5'-end oligolabeling is applied. To solve this, 3 '-end oligolabeling was adopted in the XPG assay.

Concerning biochemical studies in vitro, XPG functions as a structure-specific endonuclease and makes efficient incisions on bubble-shaped substrate $(5,10)$. In this study, endonucleolytic activity on bubble-substrate was an intrinsic property of XPG. This notion is consistent with results that XPG-derived nuclear extract displayed efficient incision on bubble-substrate, yielding a cleaved product with expected mobility (Figs. 1B and 2) in a time- and dose-dependent manner (Fig. 2A and B, respectively).

As presented in Fig. 3A, use of $7 \mathrm{mM} \mathrm{MgCl}_{2}$ yielded the optimal cleavage reaction. This might have been due to different substrate conformations under varying salt concentrations. $\mathrm{MnCl}_{2}$ had less of an effect on XPG nuclease activity relative to $\mathrm{MgCl}_{2}$ (Fig. 3B), implying that $\mathrm{MgCl}_{2}$ was the preferential cofactor for further XPG cleavage. Consistent with previous observations, the endonucleolytic reaction with purified XPG displayed both $\mathrm{MgCl}_{2}$ and $\mathrm{MnCl}_{2}$ dependency $(5,12)$. This feature might imply that the presence of both divalent metal ions was required for DNA binding, thereby yielding the active conformation of the XPG-DNA complex (12). As shown in Fig. 3C, the XPG endonuclease assay reconstituted with buffer pH 6.8 mediated more efficient cleavage compared to buffer $\mathrm{pH}$ 7.9. The low pI (5.2) of XPG might be able to explain the higher cleavage observed in reaction buffer at $\mathrm{pH} 6.8$ than at pH 7.9 (16).

It is noteworthy that the presence of ERCC1-XPF somehow enabled efficient 3 ' incision by XPG, implying that ERCC1-XPF was required for XPG cleavage. In agreement with previous evidence, during the initial formation of the dual incision complex, XPG possesses weak nuclease activity, whereas its full endonucleolytic form emerges after ERCC1-XPF has made a $5^{\prime}$ incision $(13,20)$. In contrast, the 5 ' incision by ERCC1-XPF is efficiently achieved in the presence of functionally inactive XPG. One possible explanation is that the XPG-mediated 3 incision might be triggered by a conformational change in the NER complex caused by the 5 ' incision activity of ERCC1-XPF. Based on these reasons, the existence of ERCC1-XPF in the nuclear protein portion might be advantageous for facilitating the efficient XPG cleavage activity in our modified assay.

Herein, our modification allowed for quantitative analysis with endogenous native XPG protein, based on the observation that DNA incision activity was higher in normal XPG cells compared to XPG-defective cells, in accordance with XPG protein levels (Fig. 4). The advantages of our technique based on direct application of nuclear XPG extract include: 1) no laborious overexpression and purification steps for recombinant protein; 2) relatively low cost; 3) ease of application; 4) substantial flexibility for testing diverse types of cells; 5) relatively low amounts of DNA substrate used; and 6) short period needed to complete the experiment. Assays of XPG activity and evaluations of reaction parameters are of great importance in the fields of clinical diagnostics, drug discovery, and cancer therapy. The application of this assay is therefore useful for evaluating XPG activity in response to environmental toxicants (UV irradiation or chemical mutagens) in the area of environmental or occupational toxicology. In our approach, XPG assay involving immediate use of XPG-derived nuclear extract was successfully established while maintaining its reproducibility and sensitivity. Thus, our methodology can be further adapted for simultaneous evaluation in cells or tissues of interest. However, the search for a continuous, homogeneous assay for economical, non-radioactive-based detection using this endonuclease is of interest.

\section{Acknowledgements}

This study was supported by a grant from the Basic Science Research Program though the National Research Foundation of Korea (NRF) funded by the Ministry of Education, Science and Technology, Korea (No. 2010-0013571). Additionally, this study was supported by a grant from the Ministry of Environment, Korea (2010-090001-0083-0).

\section{References}

1. Sancar A and Tang M-S: Nucleotide excision repair. Photochem Photobiol 57: 905-921, 1993.

2. Schärer D: XPG: its products and biological roles. Adv Exp Med Biol 637: 83-92, 2008

3. Vermeulen W, Jaeken J, Jaspers NG, Bootsma D and Hoeijmakers JH: Xeroderma pigmentosum complementation group G associated with Cockayne syndrome. Am J Hum Genet 53: $185-192,1993$.

4. O'Donovan A, Davies AA, Moggs JG, West SC and Wood RD: XPG endonuclease makes the $3^{\prime}$ incision in human DNA nucleotide excision repair. Nature 371: 432-435, 1994.

5. Evans E, Fellow J, Coffer A and Wood RD: Open complex formation around a lesion during nucleotide excision repair provides a structure for cleavage by human XPG protein. EMBO 16: 625-638, 1997.

6. Lieber MR: The FEN-1 family of structure-specific nucleases in eukaryotic DNA replication, recombination and repair. Bioessays 19: 233-240, 1997.

7. Mueser TC, Nossal NG and Hyde CC: Structure of bacteriophage T4 RNase H, a 5' to 3' RNA-DNA and DNA-DNA exonuclease with sequence similarity to the RAD2 family of eukaryotic proteins. Cell 85: 1101-1112, 1996.

8. Mu D, Hsu DS and Sancar A: Reaction-mechanism of human DNA-repair excision nuclease. J Biol Chem 271: 8285-8294, 1996.

9. Matsunaga T, Mu D, Park CH, Reardon JT and Sanca A: Human DNA repair excision nuclease. Analysis of the roles of the subunits involved in dual incisions by using anti-XPG and antiERCC1 antibodies. J Biol Chem 270: 20862-20869, 1995.

10. Habraken Y, Sung P, Prakash L and Prakash S: Human xeroderma pigmentosum group $G$ gene encodes a DNA endonuclease. Nucleic Acids Res 22: 3312-3316, 1994.

11. O'Donovan A, Scherly D, Clarkson SG and Wood RD: Isolation of active recombinant XPG protein, a human DNA repair endonuclease. J Biol Chem 269: 15965-15968, 1994.

12. Hohl M, Thorel F, Clarkson SG and Schärer OD: Structural determinants for substrate binding and catalysis by the structurespecific endonuclease XPG. J Biol Chem 278: 19500-19508, 2003. 
13. Constantinou A, Gunz D, Evans E, Lalle P, Bates PA, Wood RD and Glarkson SG: Conserved residues of human XPG protein important for nuclease activity and function in nucleotide excision repair. J Biol Chem 274: 5637-5648, 1999.

14. Mocquet V, Laine JP, Riedl T, Yajin Z, Lee MY and Egly JM: Sequential recruitment of the repair factors during NER: the role of XPG in initiating the resynthesis step. EMBO J 27: 155-167, 2008.

15. Wakasugi M, Reardon JT and Sancar A: The non-catalytic function of XPG protein during dual incision in human nucleotide excision repair. J Biol Chem 272: 16030-16034, 1997.

16. Dunand-Sauthier I, Hohl M, Thore F, Jaquier-Gubler $P$ Clarkson SG and Schärer OD: The spacer region of XPG mediates recruitment to nucleotide excision repair complexes and determines substrate specificity. J Biol Chem 280: 7030-7037, 2005 .
17. Klungland A, Höss M, Gunz D, Constantinou A, Clarkson SG, Doetsch PW, Bolton PH, Wood RD and Lindahl T: Base excision repair of oxidative DNA damage activated by XPG protein. Mol Cell 3: 33-42, 1999.

18. Tian M, Jones DA, Smith M, Shinkura R and Alt FW: Deficiency in the nuclease activity of xeroderma pigmentosum $\mathrm{G}$ in mice leads to hypersensitivity to UV irradiation. Mol Cell Biol 24: 2237-2242, 2004

19. Riedl T, Hanaoka F and Egly JM: The comings and goings of nucleotide excision repair factors on damaged DNA. EMBO J 22 5293-5303, 2003

20. Tapias A, Auriol J, Forget D, Enzlin JH, Schärer OD, Coin F, Coulombe B and Egly J-M: Ordered conformational changes in damaged DNA induced by nucleotide excision repair factors. J Biol Chem 279: 19074-19083, 2004. 